\title{
Linear signal processing using silicon micro-ring resonators
}

Peucheret, Christophe; Ding, Yunhong; Ou, Haiyan; Xiong, Meng; An, Yi; Lorences Riesgo, Abel; Xu, Jing; Ozolins, Oskars; Hu, Hao; Galili, Michael

Total number of authors:

16

Published in:

POEM/IONT Technical Digest

Link to article, DOI:

10.1364/IONT.2012.ITh5B.1

Publication date:

2012

Link back to DTU Orbit

Citation (APA):

Peucheret, C., Ding, Y., Ou, H., Xiong, M., An, Y., Lorences Riesgo, A., Xu, J., Ozolins, O., Hu, H., Galili, M., Huang, B., Pu, M., Ji, H., Seoane, J., Liu, L., \& Zhang, X. (2012). Linear signal processing using silicon microring resonators. In POEM/IONT Technical Digest (pp. ITh5B.1). Optical Society of America.

https://doi.org/10.1364/IONT.2012.ITh5B.1

\section{General rights}

Copyright and moral rights for the publications made accessible in the public portal are retained by the authors and/or other copyright owners and it is a condition of accessing publications that users recognise and abide by the legal requirements associated with these rights.

- Users may download and print one copy of any publication from the public portal for the purpose of private study or research.

- You may not further distribute the material or use it for any profit-making activity or commercial gain

- You may freely distribute the URL identifying the publication in the public portal 


\title{
Linear signal processing using silicon micro-ring resonators
}

\author{
Christophe Peucheret $^{1}$, Yunhong Ding ${ }^{1}$, Haiyan Ou ${ }^{1}$, Meng Xiong ${ }^{2,1}$, \\ Yi An ${ }^{1}$, Abel Lorences Riesgo ${ }^{1}$, Jing Xu ${ }^{1}$, Oskars Ozolins ${ }^{3,1}$, Hao Hu ${ }^{1}$, \\ Michael Galili ${ }^{1}$, Bo Huang ${ }^{2,1}$, Minhao Pu${ }^{1}$, Hua $\mathbf{J i}^{1}$, Jorge Seoane ${ }^{1}$, \\ Liu Liu ${ }^{4}$ and Xinliang Zhang ${ }^{2}$ \\ ${ }^{1}$ DTU Fotonik, Technical University of Denmark, DK-2800 Kgs. Lyngby, Denmark \\ 2 Wuhan National Laboratory for Optoelectronics, 430074 Wuhan, China \\ ${ }^{3}$ Telecommunications Institute, Riga Technical University, LV-1048 Riga, Latvia \\ ${ }^{4}$ South China Normal University, 510006 Guangzhou, China \\ cpeu@fotonik.dtu.dk
}

\begin{abstract}
We review our recent achievements on the use of silicon micro-ring resonators for linear optical signal processing applications, including modulation format conversion, phase-to-intensity modulation conversion and waveform shaping.
\end{abstract}

(C) 2012 Optical Society of America

OCIS codes: (130.3120) Integrated optics devices; (130.7408) Wavelength filtering devices

Silicon micro-ring resonators (MRRs) are compact and versatile devices whose periodic frequency response can be exploited for a wide range of applications, the most straightforward being periodic filters, add-drop multiplexers or wavelength selective switches [1]. Recently, we have exploited the design flexibility of MRRs in order to demonstrate spectral and temporal signal shaping. In particular, MRRs can be used for optical modulation format conversion from return-to-zero (RZ) on-off keying (OOK) to non-return-to-zero (NRZ) OOK [2]. This technique has been used for multi-channel format conversion, but also for the first ever demonstration of NRZ signal generation at $640 \mathrm{~Gb} / \mathrm{s}$ by conversion of an optical time division multiplexed (OTDM) signal [3]. It has also been extended to format conversion from RZ differential phase-shift keying (DPSK) to NRZ-DPSK [4]. Another application of MRRs is for the demodulation of DPSK signals [5]. Other temporal shaping demonstrations include the generation of ultra-wideband monocycle pulses [6] as well as the enhancement of the modulation speed of directly modulated lasers [7].

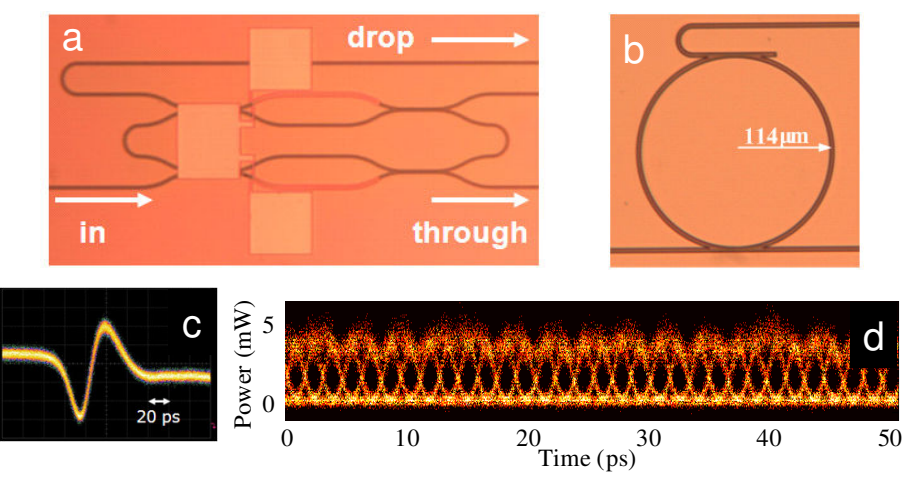

Fig. 1. Microscope pictures of (a) micro-ring resonator with tunable coupling coefficients for UWB signal generation and (b) add-drop micro-ring resonator used for multi-channel DPSK demodulation at $40 \mathrm{~Gb} / \mathrm{s}$. (c) Synthesised Gaussian monocycle pulse. (d) Eye diagram of a 640 Gbit/s NRZ-OOK signal obtained by modulation format conversion of an OTDM RZ-OOK signal.

Even though silicon MRRs are promising devices, they suffer from inherent polarization sensitivity, which is a critical impediment to their practical use. We will show how polarization diversity circuits based on polarization splitters and rotators can be engineered to significantly reduce their polarization sensitivity and illustrate the benefit of such circuits with the example of an MRR-based DPSK demodulator [8].

\section{References}

1. W. Bogaerts et al., Laser Photonics Rev. 6, 47-73 (2012).

2. Y. Ding, et al, Opt. Express 18, 21121-21130 (2010).

3. Y. Ding et al., Opt. Express 19, 6471-6477 (2011).

4. M. Xiong et al., OECC (2012), paper SC2-1085.
5. Y. Ding et al., J. Lightwave Technol. 29, 677-684 (2011).

6. Y. Ding, et al., IPC (2011), paper TuI2.

7. Y. An et al., OECC (2012), paper SC2-1086.

8. Y. Ding et al., IEEE Photon. Technol. Lett. 23, 1808-1810 (2011). 